\title{
MÉTODOS DE EXTRAÇÃo DE SEMENTES DE MANGABA VISANDO À QUALIDADE FISIOLÓGICA ${ }^{1}$
}

\author{
DANIELLA INÁCIO BARROS², RISELANE DE LUCENA ALCÂNTARA BRUNO ${ }^{3}$ HELBER VÉRAS NUNES², \\ GERCIANE CABRAL DA SILVA ${ }^{4}$, WALTER ESFRAIN PEREIRA ${ }^{5}$, REJANE MARIA NUNES MENDONÇA ${ }^{3}$
}

\begin{abstract}
RESUMO - A mangaba (Hancornia speciosa Gomes) tem a via sexuada como principal forma de propagação. São escassas as pesquisas referentes à extração de suas sementes; entretanto, a viabilidade e o vigor dependem diretamente do método empregado. O presente trabalho teve como objetivo avaliar a qualidade fisiológica de sementes de mangaba extraídas sobre três métodos, sendo um manual (peneira) e outros dois mecânicos (despolpadeira e batedeira). Em seguida, as sementes foram submetidas aos testes de umidade, germinação, condutividade elétrica, primeira contagem, emergência de plântulas em areia e massa seca de plântulas. A extração manual proporcionou sementes com maior qualidade fisiológica, e entre os métodos mecânicos, a batedeira resultou em sementes mais viáveis e vigorosas, enquanto a despolpadeira provocou danos agudos.

Termos para indexação: Hancornia speciosa, semente, viabilidade, vigor.
\end{abstract}

\section{DIFFERENT EXTRACTION METHODS AIMING MANGABA SEEDS QUALITY}

\begin{abstract}
Mangaba (Hancornia speciosa Gomes) has the sexual way as the main propagation form. Researches regarding the extraction of its seeds are scarce; however, viability and vigor depend directly on the applied method. The present work had as objective to evaluate physiologic quality of extracted mangaba seeds on three methods, in which one is manual (drizzles) and the other two are mechanical (content removing device and mixer), further the mentioned seeds were submitted to humidity, germination, electric conductivity, first count, seedling emergence and seedlings dry mass tests. Manual extraction provided seeds with a larger physiologic quality and, among mechanical methods; the mixer resulted in viable and vigorous seeds, while the content removing device caused sharp damages.
\end{abstract}

Index terms: Hancornia speciosa, seed, viability, vigor

\section{INTRODUÇÃO}

A mangabeira (Hancornia speciosa Gomes) é uma planta nativa do Brasil, encontra-se vegetando espontaneamente nas regiões Sudeste, Centro-Oeste, Norte e Nordeste. Na Paraíba, ocorre, predominantemente, na mesorregião da Mata Paraibana, com maior freqüência nas áreas compreendidas pelas microrregiões de João Pessoa e dos Litorais Norte e Sul (Aguiar Filho \& Bosco, 1998). Típica da faixa litorânea Nordestina, sua população vem sendo drasticamente reduzida, juntamente com o restante da vegetação nativa, devido à especulação imobiliária e ao desmatamento para o cultivo de monoculturas, principalmente coqueiro, cana-de-açúcar e pastagens (Vieira, 1998).

Considerando que se trata de uma cultura ainda em fase de domesticação, temas como avaliação da qualidade fisiológica das sementes, seleção de genótipos, desenvolvimento e adaptação de práticas culturais e aspectos relacionados com a pré e pós-colheita do fruto, entre outros, necessitam ser mais bem investigados. Esse quadro de abandono e destrato das mangabeiras existentes tem sido, por outro lado, amenizado pelo interesse de alguns produtores em iniciar um plantio estruturado sob bases comerciais, estimulados pela grande demanda e bons preços alcançados no mercado informal.

Os frutos dessa espécie são do tipo baga, de tamanho, formato e cores variados, normalmente, elipsoidais ou arredondados, amarelados ou esverdeados, com pigmentação vermelha ou sem pigmentação, polpa amarela adocicada, rica em vitaminas, ferro, fósforo, cálcio e proteínas (Aguiar Filho \& Bosco, 1998). Suas sementes são achatadas e discóides, com coloração castanho-clara (Lederman et al., 2000).

A extração das sementes pode ser manual ou mecânica, desde que sejam utilizados frutos sadios e maduros, apresentando casca amarela ou verde-amarelada, com manchas avermelhadas e consistência macia ou mole, colhidos logo depois da sua queda ao chão (Parente et al., 1986). Contudo, a qualidade fisiológica das sementes é afetada pela polpa aderida à semente, método de extração, cor e tamanho do fruto, armazenamento e dessecação (Tavares, 1960; Pimentel \& Santos, 1978;
Parente \& Machado, 1986; Vieira Neto, 1997; Queiroz \& Bianchetti, 2001; Bruno et al., 2004). Estudos têm revelado que as sementes devem ser semeadas o mais rapidamente após serem extraídas do fruto, não sendo recomendado o uso de sementes que tenham sido despolpadas há mais de sete dias, pois o seu vigor pode já estar comprometido (Pimentel \& Santos, 1978).

Diante do exposto, o presente trabalho teve como objetivo avaliar a qualidade fisiológica de sementes de mangaba extraídas sobre diferentes métodos.

\section{MATERIAL E MÉTODOS}

Este experimento foi conduzido no Laboratório de Análise de Sementes do Centro de Ciências Agrárias da Universidade Federal da Paraíba, em Areia - PB, no período de março a junho de 2004. Para tanto, foram utilizados frutos de mangaba provenientes da Estação Experimental de Mangabeira, pertencente à Empresa Estadual de Pesquisa Agropecuária da Paraíba - EMEPA, localizada em João Pessoa - PB. As sementes foram retiradas de frutos maduros coletados logo após caírem ao solo. Foram estudados três métodos de extração das sementes de mangaba, sendo um manual (peneira) e outros dois mecânicos (despolpadeira e batedeira). Na extração manual, os frutos foram macerados em peneira de palha; na despolpadeira, os frutos foram separados em polpa e sementes, e na batedeira, as sementes saíam misturadas à polpa. Nos três métodos de extração, as sementes foram lavadas em água corrente até a retirada total da polpa aderida. Em seguida, foram desinfetadas com solução de hipoclorito de sódio a $0,5 \%$, e, para retirar o excesso de água, foram espalhadas sobre papel toalha, permanecendo à sombra por 24 horas.

A avaliação da qualidade fisiológica das sementes foi determinada pelos seguintes testes:

Umidade (U) - o grau de umidade das sementes foi avaliado pelo método da estufa a $105 \pm 3{ }^{\circ} \mathrm{C}$ (Brasil, 1992), utilizando-se de quatro subamostras de 25 sementes.

\footnotetext{
(Trabalho 138/2005). Recebido: 05/09/2005. Aceito para publicação: 31/03/2006. Apoio: CNPq. Parte da tese de doutorado do primeiro autor

${ }^{2}$ Eng $^{\circ}$ Agr $^{\circ}$, aluno de Doutorado, do Programa de Pós-Graduação em Agronomia, Depto. de Fitotecnia, CCA/UFPB, Areia-PB, Bolsistas CNPq, danyinacio@yahoo.com.br; helberveras@yahoo.com.br

${ }^{3}$ Eng $^{\mathrm{O}} \mathrm{Agr}^{\circ}$. Dr. Prof. do Programa de Pós-Graduação em Agronomia, Depto. de Fitotecnia, CCA/UFPB, Areia-PB, Cep.58397-000, Bolsista CNPq. lane@cca.ufpb.br

${ }^{4}$ Engenheira Agrônoma - Empresa Estadual de Pesquisa Agropecuária da Paraíba - Emepa - PB.

${ }^{5}$ Eng $^{\circ}$ Agr $^{\circ}$. Dr. Prof. do Programa de Pós-Graduação em Agronomia, Depto. de Ciências Fundamentais e Sociais do CCA/UFPB, Areia-PB
} 
Germinação (G) - realizado com quatro subamostras de 50 sementes que, antes do início do teste, foram tratadas com o fungicida Benlate (Benomil - 500) na concentração de 1,0 g/kg de sementes, em seguida distribuídas em folhas de papel "germitest", umedecidas com água destilada numa quantidade equivalente a 2,5 vezes o peso do substrato seco (Brasil, 1992), sendo os rolos confeccionados e mantidos em germinador a $28^{\circ} \mathrm{C}$. Diariamente, foram realizadas observações na porcentagem de plântulas anormais, sementes duras e sementes mortas.

Primeira contagem de germinação (PCG) - conduzida juntamente com o teste de germinação, sendo a contagem realizada no décimo quinto dia após a semeadura, e os resultados expressos em porcentagem de plântulas normais (Nakagawa, 1999).

Condutividade elétrica (CE) - utilizou-se de quatro subamostras de 50 sementes, determinada através da pesagem de sementes (em balança de precisão de $0,01 \mathrm{~g}$ ), colocadas para embeber em copos plásticos contendo $75 \mathrm{~mL}$ de água deionizada, a $25^{\circ} \mathrm{C}$, durante 24 horas, conforme metodologia de Vieira (1994).

Emergência de plântulas em areia (EPA) - conduzida em casa de vegetação, onde as sementes também foram tratadas com fungicida Benlate (Benomil-500), na mesma concentração; posteriormente, quatro subamostras de 50 sementes foram distribuídas em bandejas plásticas contendo areia esterilizada e umedecida com a quantidade de água equivalente a $60 \%$ da capacidade de retenção.

Massa seca de plântula (MSP) - realizada ao final do teste de emergência em areia, sendo as plântulas colocadas em sacos de papel e levados para estufa com circulação de ar forçado, mantidas à temperatura de $65^{\circ} \mathrm{C}$, onde permaneceram até atingir peso constante. Os resultados foram expressos em gramas por plântula, conforme recomendações de Nakagawa (1994).

O delineamento estatístico utilizado foi o inteiramente casualizado, com quatro repetições, e os resultados obtidos submetidos à análise de variância, sendo as médias comparadas por meio de contrastes ortogonais.

\section{RESULTADOS E DISCUSSÃO}

Os valores médios de umidade, germinação, plântulas anormais, sementes duras e mortas, condutividade elétrica, primeira contagem de germinação, emergência de plântulas em areia e massa seca de plântulas de mangaba estão apresentados na Tabela 1. Independentemente do método de extração, a umidade, a germinação e a emergência de plântulas de mangaba em areia foram altas, variando de 46,2 a 50,4\%; de 73,0 a $86,0 \%$, e de 80 a $88 \%$, respectivamente. Barros et al. (2003), estudando diferentes métodos de secagem de sementes de mangaba, verificaram que o seu teor de umidade, na ocasião da instalação do ensaio, estava em torno de $43 \%$. Parente \& Machado (1986) verificaram que as sementes obtidas de frutos maduros apresentaram germinação em torno de $86 \%$.

As sementes retiradas na peneira, com umidade $3,1 \%$ maior em relação às extraídas mecanicamente, apresentaram a mesma porcentagem de germinação (Tabela 2). Oliveira \& Valio (1992)
TABELA 1 - Médias de umidade (\%), germinação (\%), plântulas anormais (\%), sementes duras e mortas (\%), condutividade elétrica (iS/cm/g), primeira contagem de germinação (\%), emergência de plântulas em areia (\%) e massa seca de plântula (g) de mangaba submetidas a diferentes métodos de extração.

\begin{tabular}{lccc}
\hline \multirow{2}{*}{ Variáveis } & \multicolumn{3}{c}{ Métodos de extração } \\
\cline { 2 - 4 } & Peneira & Despolpadeira & Batedeira \\
\hline Umidade & 50,3 & 46,2 & 48,2 \\
Germinação & 80,0 & 73,0 & 86,0 \\
Plântulas anormais & 10,5 & 14,0 & 6,0 \\
Sementes duras & 4,5 & 6,0 & 1,5 \\
Sementes mortas & 5,0 & 7,5 & 6,5 \\
Condutividade elétrica & 24,5 & 23,5 & 15,4 \\
Primeira contagem de germinação & 36,7 & 32,5 & 40,7 \\
Emergência de plântulas em areia & 84,0 & 88,0 & 80,0 \\
Massa seca de plântulas & 0,1 & 0,1 & 0,2 \\
\hline
\end{tabular}

observaram redução na germinação de sementes de mangaba com nível de umidade abaixo de 25 \%. Pimentel \& Santos (1978), estudando o efeito de diferentes tratamentos para a retirada total da polpa aderida às sementes de mangaba, constataram que o método da peneira foi o mais recomendado. Contudo, as sementes extraídas na batedeira apresentaram umidade $(2,0 \%)$ e germinação $(13,5 \%)$ superiores às da despolpadeira. Esta diferença na germinação, provavelmente, não está relacionada ao teor de umidade, mas sim a danos na semente causados durante a extração pela despolpadeira, ocorrendo maior porcentagem de plântulas anormais (8,0 \%). Tavares (1960), estudando o efeito de resíduos de polpa aderidos a sementes de mangaba, verificou que os mesmos inibem a germinação.

Observaram-se alterações da condutividade elétrica (CE) em todos os métodos de extração das sementes de mangaba, e da primeira contagem de germinação (PCG) entre os métodos mecânicos, com maiores valores de condutividade $(5,1$ e $8,1 \mathrm{iS} / \mathrm{cm} / \mathrm{g})$ para as sementes extraídas na peneira e na despolpadeira, respectivamente, e $8,2 \%$ menores do que na primeira contagem de germinação, nas sementes extraídas pela despolpadeira. Tais resultados indicam que a extração das sementes na peneira, apesar de ter ocasionado pequena alteração nos sistemas de membranas, não promoveu redução na viabilidade e no vigor das sementes, confirmada pelas porcentagens semelhantes de germinação, plântulas anormais, sementes duras e mortas, emergência de plântulas em areia e massa seca de plântulas, enquanto na despolpadeira estas alterações foram mais acentuadas, proporcionando aumento na lixiviação de solutos celulares.

\section{CONCLUSÕES}

1. A extração manual proporcionou sementes com maior qualidade fisiológica.

2. Sementes de mangaba extraídas na batedeira, em relação à despolpadeira, apresentaram maior viabilidade e vigor.

TABELA 2 - Estimativas dos contrastes de umidade (\%), germinação (\%), plântulas anormais (\%), sementes duras e mortas (\%), condutividade elétrica (ì $/ \mathrm{cm} / \mathrm{g})$, primeira contagem de germinação (\%), emergência de plântulas em areia (\%) e massa seca de plântula (g) de mangaba submetidas a diferentes métodos de extração.

\begin{tabular}{lcc}
\hline \multicolumn{1}{c}{ Variáveis } & \multicolumn{2}{c}{ Estimativas dos contrastes } \\
\cline { 2 - 3 } & Peneira vs Despolpadeira e Batedeira & Despolpadeira vs Batedeira \\
\hline Umidade & $3,1^{* *}$ & $-2,0^{* *}$ \\
Germinação & $0,7^{\mathrm{ns}}$ & $-13,5^{* *}$ \\
Plântulas anormais & $0,5^{\mathrm{ns}}$ & $8,0^{* *}$ \\
Sementes duras & $0,7^{\mathrm{ns}}$ & $4,5^{*}$ \\
Sementes mortas & $-2,0^{\mathrm{ns}}$ & $1,0^{\mathrm{ns}}$ \\
Condutividade elétrica & $5,1^{* *}$ & $8,1^{* *}$ \\
Primeira contagem de germinação & $0,1^{\mathrm{ns}}$ & $-8,2^{* *}$ \\
Emergência de plântulas em areia & $0,0^{\mathrm{ns}}$ & $8,0^{\mathrm{ns}}$ \\
Massa seca de plântulas & $-0,04^{\mathrm{ns}}$ & $-0,06^{\mathrm{ns}}$ \\
\hline
\end{tabular}

ns, $\mathrm{e}^{* *}=$ Não significativo, significativo a 5 e $1 \%$ de probabilidade, respectivamente, pelo teste $\mathrm{F}$. 
3. A despolpadeira provocou danos agudos nas sementes de mangaba.

\section{REFERÊNCIAS}

AGUIAR FILHO, S.P.; BOSCO, J. A mangabeira (Hancornia speciosa): domesticação e técnicas de cultivo. João Pessoa-PB: EMEPA-PB, 1998. 26 p. (Documentos, 24).

BARROS, D.I.; BRUNO, R.L.A.; MENDONÇA, R.M.N.; NUNES, H.V.; PEREIRA, W.E.; FRANCO, C.F.O.; FONTINELLI, S.C. Germinação de sementes de mangaba (Hancornia speciosa Gomes) em diferentes substratos e temperaturas. In: SIMPÓSIO BRASILEIRO SOBRE A CULTURA DA MANGABA, 1., 2003, Aracaju-SE. Resumos... Aracaju-SE: SBCM, 2003. CD-ROM.

BRASIL. Ministério da Agricultura e Reforma Agrária. Regras para análise de sementes. Brasília-DF: SNDA/DNPV/CLAV, 1992. 365 p.

BRUNO, R.L.A.; BARROS, D.I.; NUNES, H.V.; SILVA, G.C.; PEREIRA, W.E. MENDONÇA, R.M.N. Métodos de extração e suas implicações sobre a qualidade fisiológica de sementes de mangaba. In: CONGRESSO BRASILEIRO DE FRUTICULTURA, 18., 2004. Florianópolis. p. 1-4. CD ROM.

LEDERMAN, I.E.; SILVAJÚNIOR, J.F.; BEZERRA, J.E.F.; ESPÍNDOLA, A.C.M. Mangaba (Hancornia speciosa Gomes). Jaboticabal: Funep, 2000.35 p.

NAKAGAWA, J. Testes de vigor baseados na avaliação de plântulas. In: KRZYZANOWSKI, F.C.; VIEIRA, R.D.; FRANÇA NETO, J.B. (Ed.). Vigor de sementes: conceitos e testes. Londrina: ABRATES, 1999. p. 2.1-2.23.

NAKAGAWA, J. Testes de vigor baseados na avaliação das plântulas. In: VIEIRA, R.D.; CARVALHO, N.M. de. Testes de vigor em sementes. Jaboticabal-SP: FUNEP, p. 49-85, 1994.
OLIVEIRA, L.M.Q.; VALIO, I.F.M. Effects of moisture contention germination of seeds of Hancornia speciosa Gom. (Apocynaceae). Annals of Botany, London, v. 69, p. 1-5, 1992.

PARENTE, T.V.; BORGO, L.A.; MACHADO, J.W.B. Características físico-químicas de frutos de mangaba (Hancornia speciosa Gomes.) do cerrado da região geoeconômica do Distrito Federal. Ciência e Cultura, São Paulo-SP, v. 37, n. 1, p. 95-98, 1986.

PARENTE, T.V.; MACHADO, J.W.B. Germinação de sementes de mangaba (Hancornia pubescens Nees e Mart.) provenientes de frutos colhidos com diferentes graus de maturação. Revista Brasileira de Fruticultura, Cruz das Almas, v. 8, n. 1, p. 39-43, 1986.

PIMENTEL, M.L.; SANTOS, E.O. Preservação do poder germinativo de sementes de mangaba (Hancornia speciosa Gomes). Recife: IPA, 1978, 5 p. (Comunicado Técnico, 1).

QUEIROZ, J.A.L. de; BIANCHETTI, A. Armazenamento de sementes de mangaba. Informativo ABRATES, Brasília, v. 11, n. 2, p. 81, set. 2001.

TAVARES, S. Estudos sobre germinação de sementes de mangaba, Hancornia speciosa Gomes. Arquivos do Instituto de Pesquisas Agronômicas, Recife, v. 5, p. 193-199. 1960.

VIEIRA, R.D. Teste de condutividade elétrica. In: VIEIRA, R.D.; CARVALHO, N.M. de. Testes de vigor em sementes. JaboticabalSP: FUNEP, 1994. p.103-132.

VIEIRA, D. Efeito de diferentes substratos na formação de mudas de mangabeira (Hancornia speciosa Gomes). Revista Brasileira de Fruticultura, Cruz das Almas, v. 20, n. 3, p. 265-271, 1998.

VIEIRA NETO, R.D. Caracterização física de frutos de uma população de mangabeiras (Hancornia speciosa Gomes). Revista Brasileira de Fruticultura, Cruz das Almas, v. 19, n. 2, p. 247-250, 1997. 